\title{
Geohazards Inventory in Central Asia Using the Geohazard Mapping Module of the FAO Collect Earth and Earth Map Tools
}

\author{
Nazarkulov, K., ${ }^{1}$ Koshoev, M., ${ }^{2}$ Toktomametova, J. ${ }^{1}$ and Sakyev, D. ${ }^{3}$ \\ ${ }^{1}$ FAO Country office in Bishkek, 201, Akhunbaev Street, Bishkek, Kyrgyz Republic \\ E-mail: kydyr.nazarkulov@fao.org, jyldyz.toktomametova@fao.org \\ ${ }^{2} \mathrm{FAO}$ headquarter in Rome, Viale delle Terme di Caracalla, 00153 Roma RM, Italy \\ E-mail: muratbek.koshoev@fao.org \\ ${ }^{3}$ Hazard Monitoring and Forecasting Department Ministry of Emergency Situations of the Kyrgyz Republic. \\ E-mail: daur_sakyev@mail.ru
}

\begin{abstract}
Different national agencies in Central Asia assess and conduct long-term observations of dangerous geomorphological processes (geohazards) in their countries. However, these surveys are being conducted predominantly on those sites where direct threats and risks to the population or to critical infrastructure are observed. Neither field data acquisition nor regular remote sensing based observations cover the entire territory of Central Asia countries. With the recent developments in Earth Observation and cloud technologies, these observations and monitoring easily cover entire countries or regions. In this case study, the authors demonstrate the benefit of using the FAO Collect Earth and Earth Map tools for monitoring of geohazards in the Uzgen region of Kyrgyzstan.It is argued that by integrating the knowledge, skills and experience of local experts with the latest developments in EO and cloud computing, geohazards mapping will be carried out with high accuracy and without big financial investment. This study aims to outline good practice for data management that will ensure the required quality of information produced within this study. The successful result of this case study will be a starting point for broad use of this approach for observation and monitoring of geohazards, and for developing a Geohazards Inventory in Kyrgyz Republic and further in Central Asia.
\end{abstract}

\section{Introduction}

A geohazard is a natural phenomenon that may lead to widespread damage or risk. Geohazard mapping is the primary step for its investigation, prevention and early warning. The latest official maps of dangerous geomorphological processes on a scale of 1: 500,000 covering the entire territory of Kyrgyzstan were created in the late 1980s or almost 50 years ago. Maps assessed the danger of only certain processes like avalanches, mudflows, landslides and flash floods, and, for example, did not include such a dangerous process as solifluction, slope debris flow etc. Currently, the agricultural sector is largely overlooked in preparing for natural disasters and is given very limited attention in Disaster Risk Reduction (DRR). Despite the implementation of a number of projects, programs and initiatives, there are still no examples demonstrating capacity building in the field of DRR at the national, regional and community levels with a focus on the agricultural sector. The Hazard Monitoring and Forecasting Department of the Ministry of Emergency Situations monitor and conduct long-term observations of dangerous geomorphological processes in the country, including the Uzgen region. However, monitoring is being conducted only on those sites with potential threats and risks to the population or infrastructure. Neither field nor remote regular observations cover agricultural and forest lands. The Kyrgyz Republic lacks an integrated approach to disaster risk reduction (DRR) in agriculture, as scarce resources are concentrated on major disasters and crises, while small and medium-sized emergencies occuring often have a long term negative impact on agricultural development. The agricultural sector is largely overlooked in preparing for natural disasters and DRR planning, as the main institutional participants in DRR have insufficient experience in the agricultural sector (Ministry of Emergencies, Institute of Seismology of the National Academy of Sciences, Central-Asian Institute for Applied Geosciences (CAIAG) etc.) and, on the other hand, agricultural institutions have very limited potential in DRR.

\section{Literature Review}

Accuracy and applicability of geohazards mapping with remote sensing will be significantly improved 
by exploiting Big Data. Google Earth Engine (GEE https://earthengine.google.com) is a cloud computing platform, stores huge archives of data from different satellites as well as social, demographic and weather data, digital elevation models and climate data layers for analysis and ultimately decision support. Its easily accessible and user-friendly interface provides a convenient environment for interactive data and algorithm development and allows scientists and researchers to use this data for change detection, mapping trends and so on. Different studies using GEE geospatial cloud computing tools to process large data sets for global applications have been carried out over the last 10 years. Rangeland monitoring using long term MODIS data from 2000 to 2016 in a cloud computing environment was carried out in Brasil where a total of 17 pasture land maps were produced. Results show an increase in pasture area for most areas analyzed (Parente and Ferreira, 2018). In another study, the potential of GEE for handling huge data sets at a global scale was demonstrated by extracting land surface temperature data from Landsat imagery, where more than 6000 Landsat images from 1992 to 2011 were processed (Ravanelli et al., 2018).

GEE also is used in disaster management. A flood prevention and response system was developed by Liu et al., 2018. The cloud-based engine was used for agricultural drought monitoring. It facilitates an integration of soil moisture global data sets with webbased processing tools to forecast drought duration as well as intensity. This methodology was successfully tested in South Africa and Ethiopia (Sazib et al., 2018). Mutanga and Kumar (2019) highlight that day to day, monthly, seasonal and long-term monitoring of phenomena at high spatial resolution and covering large extents is now possible with the availability of such platforms that can handle big data.

Developed by FAO, 'Collect Earth' is a user friendly, Java-based data collection tool. Collect Earth is a tool that enables data collection through Google Earth Pro. In conjunction with Google Earth Pro, Bing Maps and GEE, users can analyze high and very high resolution satellite imagery for a wide variety of purposes, including support for multiphase National Geohazards Inventories. It offers fully customizable data entry and individual or team based data collection. The Geohazard mapping module of the FAO Collect Earth tools through augmented visual interpretation allows to integrate the knowledge, skills and experience of local experts with the latest developments in Earth Observation and cloud computing. The use of Earth Observation for mapping landslide phenomena has advanced significantly in the last decades like by Bianchini et al., (2016), Hölbling et al., (2017) and Zhong et.al. (2019).

Bianchini et al., (2017) focused on landslide inventory map of Armenia and have detected 204 landslides most of them were not previously mapped. Hölbling et al., (2017) were comparing results of semi-automated object based image analysis with visual image interpretation for landslide delineation in Austria and Italy. In this research authors stressed the main disadvantages of the visual interpretation method as time-consuming process and depends on various factors. In this regard, it was necessary to involve several local experts in our study. Zhong et.al. (2019) also highlighted that for a trained interpreter - expert, visual interpretation is an simple and intuitive process that does not require sophisticated technological skills.

\section{Data and Methodology}

A Geohazards Inventory in Central Asia would provide an exceptional georeferenced database of geohazards, which is absolutely necessary for disaster risk assessment. First, the authors have decided to consider geomorphological hazards in a pilot study. Public institutions like Hazard Monitoring and Forecasting Department monitor and conduct long-term observations of all dangerous geomorphological processes in the country. Based on these observations, the total area of lands exposed to landslides is about $7.5 \%$ of the territory of the republic. The greatest number of landslides is located in Osh and Jalal-Abad regions in the southern part of country. The Uzgen region is located in the southern part of the country and due to unique geomorphological features was selected as the pilot study area. Its population is about 230000 with an area of 3400 sq.km. Agriculture is the main economic activity of the region.

The purpose of this study is to apply and test the developed methodology for implementing a geohazards inventory, data management and processing chains on pilot study area. The workflow consists of a preparation step, 2 surveys and final part (Figure 1). In this study FAO Collect Earth is used with its different components. It enables data collection through GE, Bing Maps and GEE. Users interact with Collect Earth via Google Earth Pro and can analyze High and Very High Resolution images for different purposes and at different scales. For the preparation of work for identifying dangerous sites, it was necessary to generate a 200 meter grid for whole territory of the Uzgen region using the grid generator tool of FAO Collect Earth. In total around 85 thousand grids cells cover the study region. The choice of the $200 \mathrm{~m}$ grid was due to the time of the project, as well as to create a map 1:200,000. The first 
and second survey designs are prepared for the study area on the Open Foris Collect platform (http://openforis.org/). This is a survey designer providing a fast and flexible way to set up a survey with a user-friendly interface.

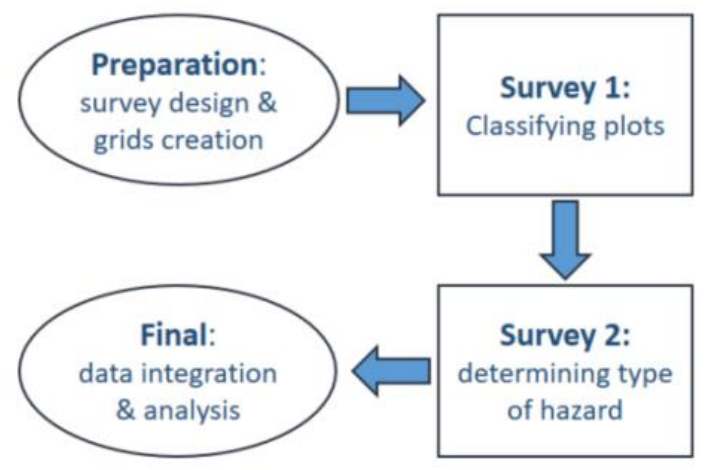

Figure 1: Workflow

Both survey designs have been adapted to local needs by considering all the features of the Uzgen region. High-resolution satellite images from 2000 until 2020 and from different sources and with slightly different scales were used for this study. Visual interpretation was carried out by assessing time series of images for each plot, a 70 by $70 \mathrm{~m}$ cell with its focus at a randomly created point inside of the cell. The aim of the first survey was to identify if a plot lies on a danger area or not, as shown on Figure 2. All 85000 plots are divided among 6 experts of the Hazard Monitoring and Forecasting Department (HMFD) of the Ministry of Emergency. The number of images per plot can be different from plot to plot. The maximum number of images covering one plot was sixteen and minimum number was four. Image type and the date of capture are also shown on the bottom of Figure 2 (Spot image from October 22, 2017). Each 70 to 70 meter plot with different images was visually interpreted and 3500 plots are categorized as hazardous.In the second survey, experts had to interpret applicable hazards from the list of 16 categories in Table 1 , based on visual interpretation and prior knowledge about the place. Working with this survey experts could choose which images to use for visual interpretation from Google Earth or Bing Maps, with Bing Maps used as the very high resolution imagery of Google Earth.

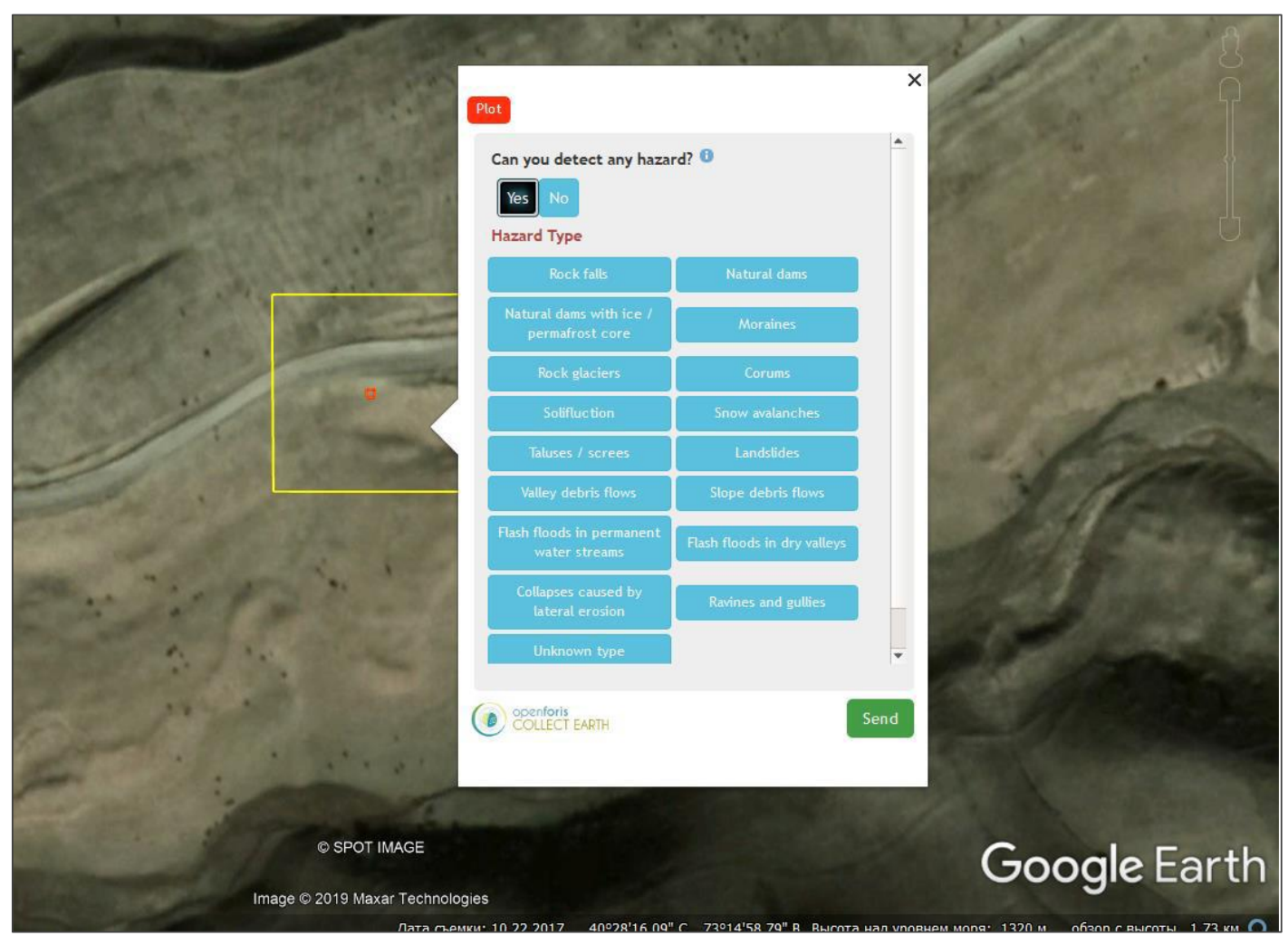

Figure 2: This is a GEE view of visual interpretation phase

GEE allows multi-temporal assessment through high resolution imagery, therefore landuse change can be detected on plot level. Each of these 3500 plots were characterized with the type of hazard, degree of danger, magnitude, and frequency of the process and additionally landuse type. FAO Collect Earth calculated certain parameters, as slope and azimut. In both surveys the Imagery Compare function of Earth 
Map (https://earthmap.org) is used as an additional tool by experts.

Table 1: Type of hazards

\begin{tabular}{|l|l|}
\hline 1 & Collapses caused by lateral erosion \\
\hline 2 & Corums \\
\hline 3 & Flash floods in dry valleys \\
\hline 4 & Flash floods in permanent water streams \\
\hline 5 & Landslides \\
\hline 6 & Moraines \\
\hline 7 & Natural dams \\
\hline 8 & Natural dams with ice/permafrost core \\
\hline 9 & Ravines and gullies \\
\hline 10 & Rock falls \\
\hline 11 & Rock glaciers \\
\hline 12 & Slope debris flows \\
\hline 13 & Snow avalanches \\
\hline 14 & Solifluction \\
\hline 15 & Talus/Scree \\
\hline 16 & Valley debris flows \\
\hline
\end{tabular}

The final part of study includes compilation of data and its integration into the geodatabase of hazardous natural processes. Based on the developed methodology geohazards were visually identified by experts for Uzgen region, including agricultural lands. All sixteen type of hazards are present in the study area. Fieldwork for validation purpose was not carried out, but experts are familiar with this region and familiar with hazards near to settlements and infrastructure. There were quite substantial differences when comparing the existing database of hazards with the results of this study. The existing database only includes endangered locations with a threat to human activities and life. Due to this, it was not possible to validate whole study area results.

\section{Results}

This research developed a new geodatabase showing the real picture of hazardous natural processes distribution in the Uzgen region (Figure 3). The study area is presented through a 200 meter grid. Each cell was estimated on 16 categories of hazards based on a times series of images from 2000 to 2020 . Figure 4 shows a landslide density map created from results of the current study, showing many hazards occuring along rivers and in mountain regions. This study has demonstrated the power of the FAO Collect Earth tool with GEE and Bing Maps in handling huge data sets at various scales and its use for geohazards mapping. At the same time, the main and time consuming part of this study was the application of expert knowledge, as they had to complete visual interpretation of all created plots with cell size $200 * 200$ meters.

\section{Conclusion}

The Ministry of Emergency Situations of the Kyrgyz Republic (MES KR) arranged the mapping of local expertise on geohazards using the Openforis Collect Earth and Collect tool within the FAO project on strengthening capacities for disaster risk reduction and disaster preparedness in the agricultural sector of the Kyrgyz Republic.

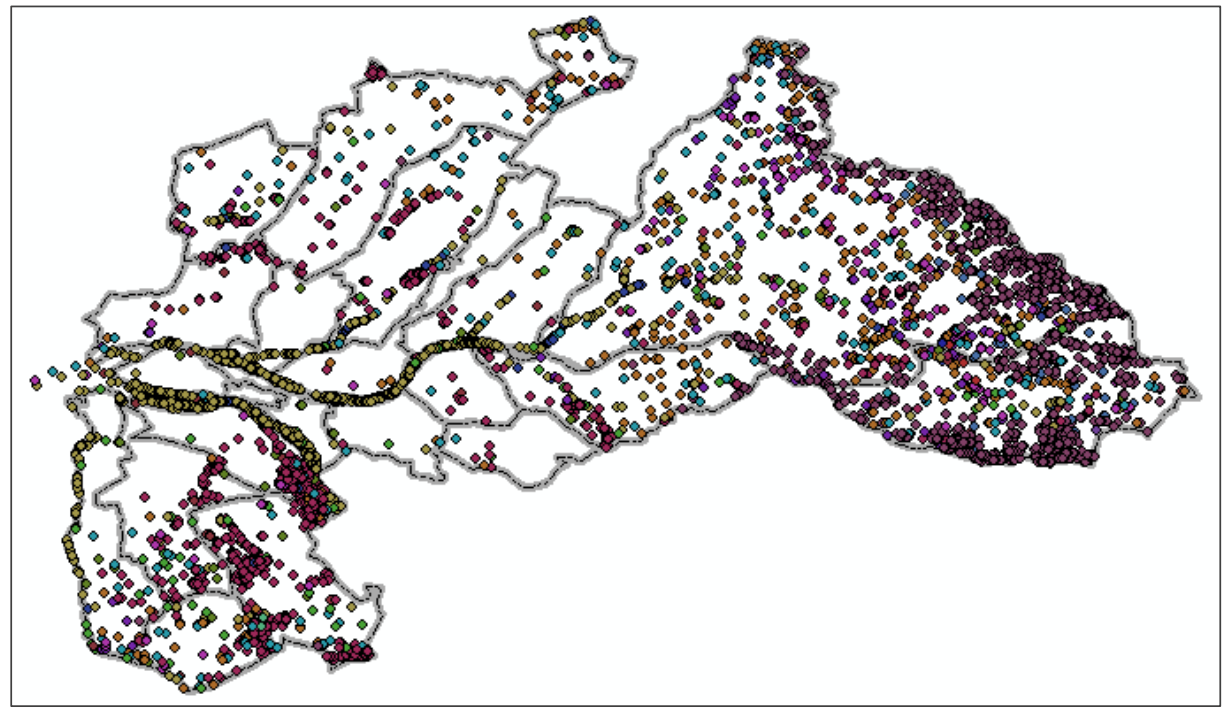

Figure 3: Geohazard distribution map-scheme of Uzgen. Results of current study 


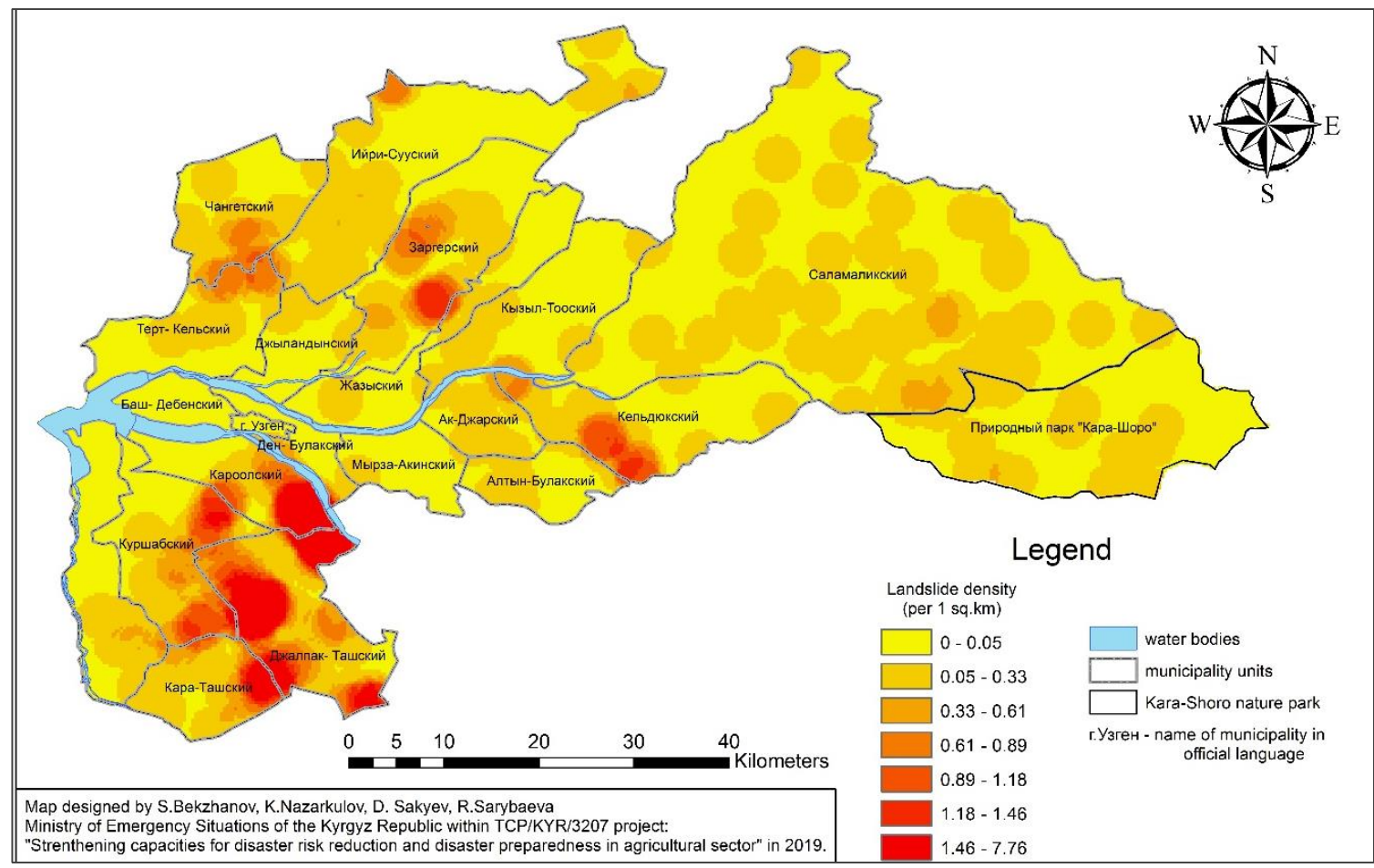

Figure 4: Landslide density map in the Jazy river basin

The project succeeded to develop spatial distribution maps of all identified geohazards for territory of Uzgen region, including agricultural lands. Mapping of geohazards for the whole territory of Kyrgyzstan created an extensive database with highly relevant results.

It is difficult to overestimate the results of the geohazards mapping for development of a comprehensive geohazards database for entire territory of the Kyrgyz Republic, which is absolutely necessary for mitigation measures, both in the agricultural sector and in other sectors, considering the exposure of the territory and population of Kyrgyzstan to geohazards. Development of geohazards database and deployment in Hazard Monitoring and Forecasting Department (HMFD) allows sharing this information with interested organization and stakeholders through web portal of HMFD. The project is built on the experience gained through the successful previous projects carried out in Brazil and Kenia and will be linked to on-going specialized programs on disaster risk management.

\section{Acknowledgements}

This study is part of the project "Strengthening capacities for disaster risk reduction and disaster preparedness in the agricultural sector" funded by UN FAOthrough its regional office for Central Asia in Ankara, Turkey. The project is implemented with the Ministry of Emergency Situations of the Kyrgyz
Republic as the leading state executive authority in partnership with regional institutions involved in DRR and climate change, local authorities, public organizations and NGOs. The authors would like to thank all project partners:

- Hazard Monitoring and Forecasting Department, MES KR;

- Agency for Hydrometeorology MES KR;

- Center for Emergency Situations and Disaster Risk Reduction, Almaty, Kazakhstan;

- UN FAO: Head Quarter in Rome, Italy; Sub-regional office for Central Asia in Ankara, Turkey; FAO country representation and offices in Central Asia

\section{References}

Bianchini, S., Raspini, F., Ciampalinia, A., Lagomarsino, D., Bianchi, B, Bellotti, F. and Casaglia, N., 2016, Mapping Landslide Phenomena in Landlocked Developing Countries by Means of Satellite Remote Sensing Data: the Case of Dilijan (Armenia) Area. Geomatics, Natural Hazards and Risk, Vol. 8(2), 225-241, https://doi.org/10.1080/19475705.2016.1189459.

Hölbling, D., Eisank, C., Albrecht, F., Vecchiotti, F., Friedl, B., Weinke, E. and Kociu, A., 2017, Comparing Manual and Semi-Automated 
Landslide Mapping Based on Optical Satellite Images from Different Sensors. Geosciences, Vol. 7(2), 37. https://doi.org/10.3390/geosciences7020037.

Liu, C. C., Shieh, M. C., Ke, M. S. and Wang, K. H., 2018, Flood Prevention and Emergency Response System Powered by Google Earth Engine. Remote Sens. Vol. 10(8), 2-20.

Mutanga O. and Kumar L, 2019, Google Earth Engine Applications. Remote Sensing, Vol. 11(5), 2-4.

Parente, L. and Ferreira, L., 2018, Assessing the Spatial and Occupation Dynamics of the Brazilian Pasturelands Based on the Automated Classification of MODIS Images from 2000 to 2016. Remote Sensing, Vol. 10(4), 1-4.
Ravanelli, R., Nascetti, A., Cirigliano, R.V., Di Rico, C., Leuzzi, G., Monti, P. and Crespi, M., 2018, Monitoring the Impact of Land Cover Change on Surface Urban Heat Island through Google Earth Engine: Proposal of a Global Methodology, First Applications and Problems. Remote Sens., Vol. 10(9), 1-21.

Sazib, N., Mladenova, I. and Bolten, J., 2018, Leveraging the Google Earth Engine for Drought Assessment Using Global Soil Moisture Data. Remote Sens., Vol. 10(8), DOI: 10.3390/rs10081265.

Zhong, C., Liu, Y., Gao, P., Chen, W., Li, H. and Hou, Y., 2019, Landslide Mapping with Remote Sensing: Challenges and Opportunities. International Journal of Remote Sensing, Vol. 41(4), 1-27. 